\title{
AlEGORIA CALIFORNIANA
}

CALIFORNIAN ALLEGORY

\section{Julio Ramos}

Universidade da Califórnia

Berkeley, EUA

Palavras-chave: Diego Rivera; linha de montagem; pós-trabalho; políticas da língua.

Palabras-Ilave: Diego Rivera; linea de montaje; pos-trabajo; políticas de la lengua

Keywords: Diego Rivera; assembly line; post-work; politics of language.

\section{Resumo}

O ensaio parte dos murais de Diego Rivera realizados nos anos 1930 nos Estados Unidos para desentranhar neles uma alegoria das relaçóes Norte e Sul, América do Norte e América Latina. A viagem do muralista mexicano aos Estados Unidos alegoriza essa relação em que se formulam estratégias de combinação entre técnica e natureza, máquina e corpo, nestes murais que representam a linha de produção fordista e a racionalização do tempo do trabalho físico. A viagem de Rivera alegoriza ainda a constituição do "latino-americanismo", como campo universitário em que se inserem as representaçôes culturalizadas da América Latina nos Estados Unidos. A partir dessa matriz o ensaio se detém sobre as políticas da língua hispânica que se inscreve como língua diaspórica nos Estados Unidos, segundo o paradigma da tradução, e encarnando-se em maneiras possíveis de convocação do corpo como corpo da língua nos poemas de Rosário Castellanos e no clássico de Pablo Neruda, "Alturas de Macchu Picchu". ,

\section{Resumen}

El ensayo parte de los murales de Diego Rivera realizados durante los años 30 en Estados Unidos para desentrañar en ellos una alegoría de las relaciones Norte y Sur, América del Norte y América Latina. El viaje del muralista mexicano a Estados Unidos alegoriza esa relación en que se formulan estrategias de combinación entre técnica y naturaleza, máquina y cuerpo, en estos murales que representan la línea de producción fordista y la racionalización del tiempo del trabajo físico. El viaje de Rivera alegoriza también la constitución del "latinoamericanismo", como campo universitario en que se insertan las representaciones cul-

\section{Abstract}

The essay takes its cue from Diego Rivera's murals accomplished in the thirties in the United States in order to localize in them an allegory of North-South relations, North America and Latin America. The Mexican muralist's trip to the United States allegorizes this relationship in which are formulated strategies for combining technology and nature, the machine and the body, in these murals which represent the Fordist production line and the racionalization of time in physical labor. Riverass trip also allegorizes the constitution of "Latin Americanism", as an Academic field in which are intro- 
turalizadas de América Latina en Estados Unidos. Partiendo de esa matriz, el ensayo se detiene sobre las políticas de la lengua hispánica que se inscribe como lengua diaspórica en Estados Unidos, según el paradigma de la traducción, y encarnándose en maneras posibles de convocación del cuerpo como cuerpo de la lengua en los poemas de Rosario Castellanos y en el clásico de Pablo Neruda, "Alturas de Macchu Picchu”. duced Cultural representations of Latin America in the United States. Drawing from this model the essay studies the politics of the Spanish language as a diasporic language in the United States, following the translation paradigm, and embodying itself in possible ways of enlisting the body as a body of language in the poems of Rosário Castellanos and Pablo Neruda's classic, "Alturas de Macchu Picchu”.

Esta foto de Ansel Adams - tirada em Artherton, Califórnia, entre 1930 e $1931^{1}$ - é uma das poucas imagens que se conhecem do afresco intitulado "Still Life and Blossoming Almond Trees" ["Natureza morta e amendoeiras em flor"], pintado por Diego Rivera durante sua primeira estadia em San Francisco.

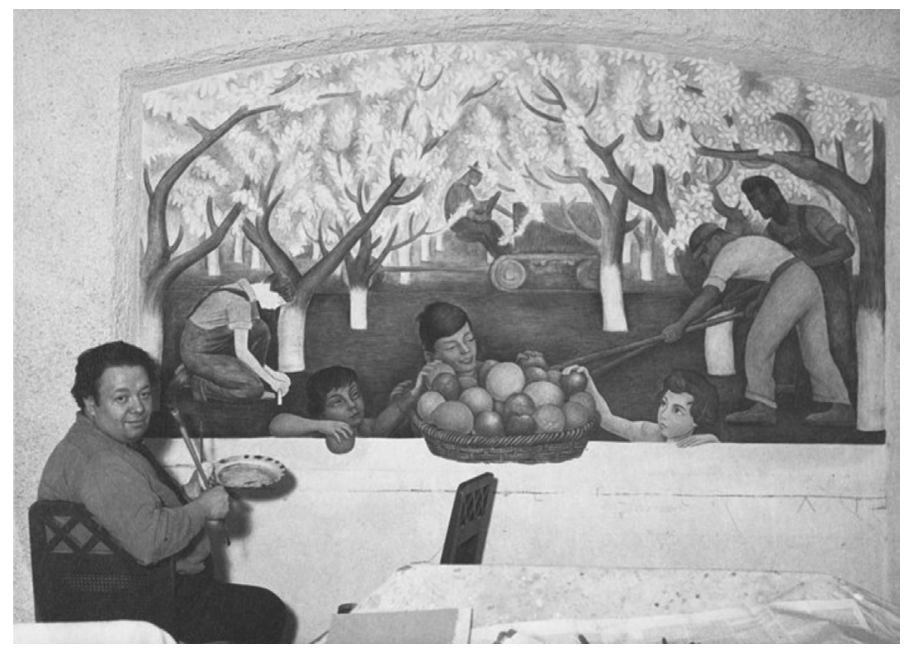

Ansel Adams. Diego Rivera Painting the Fresco "Still Life and Blossoming Almond Trees” (1930-1931) da coleção do Museu de Arte Moderna de São Francisco.

\footnotetext{
${ }^{1}$ Reproduzimo-la com a permissão de The Ansel Adams Publishing Rights Trust.
} 
* (BENJAMIN, Walter. El origen del drama barroco alemán. Trad. José Muñoz Millanes. Madrid: Taurus, 1990.)
A foto de Adams capta a textura do reboco ainda irregular (e talvez úmido) sobre o qual Rivera pintou o cultivo das amendoeiras na mansão de Sigmund e Rosalie Meyer Stern, conhecidos patronos das artes na Califórnia. Rosalie Meyer Stern, ativista cívica, encomendou o afresco em 1930 e o doou em seguida à Universidade da Califórnia, em Berkeley, em princípios dos anos 40, para a inauguração de uma nova residência universitária, Stern Hall, localizada ao pé das colinas de Berkeley. A Comissão de Representantes da Universidade da Califórnia é proprietária do afresco - exposto ao público de Stern Hall, unicamente, através de solicitação prévia. São relativamente poucos os alunos e professores de Berkeley que conhecem o pequeno - embora exemplar - mural do pintor mexicano.

É um mural sobre as condições de produção da paisagem, do trabalho agrícola, do consumo das frutas californianas e da própria arte. $\mathrm{O}$ afresco desdobra os paradoxos da natureza-morta: a condição dinâmica, performática, que possibilita a stasis da "still life" a que remete o título (em inglês). O título, aliás, condensa um notável paradoxo: a "natureza-morta" se opõe às "amendoeiras em flor" assim como as frutas no primeiro plano do afresco são antecedidas pelos planos superiores da produção e do trabalho agrícola.

Se a alegoria barroca cifrava na fruta da bodega o tempo de uma vida à beira da decomposição (a história convertida em natureza encaminhada à sua ruína ou putrefação, como diria Walter Benjamin, ${ }^{*}$ o afresco de Rivera mostra magistralmente o que a história de uma bodega não pode exibir, isto é, o trabalho e as condições de cultivo e a cultura que tornam a "natureza-morta" possível. Em outras palavras, o afresco é uma pintura sobre a arte e sua relação com a natureza, a técnica, a propriedade, o trabalho e o consumo nos complexos e sobredeterminados circuitos de criação de valor.

Outros murais de Rivera são mais conhecidos em São Francisco, sobretudo os monumentais painéis da "Unidade Panamericana" (1940) expostos no City College de São Francisco, que segundo o pintor representam o "matrimônio artístico entre o Norte e o Sul do hemisfério". Mais compacto e extraordinário ainda é o notável "Alegoria da Califórnia" (1930-1) encomendado pelo Pacific Stock Exchange (hoje o exclusivíssimo City Club); e o polêmico "The Making of a Fresco" [“A realização de um afresco"] (1930-1), 
exibido no Instituto de Arte de São Francisco. ${ }^{2}$ Estes três magníficos murais constituem, junto à obra de Detroit e ao obliterado mural do Rockefeller Center, a contribuição decisiva do viajante mexicano ao campo artístico da alta era industrial e à formação de várias geraçōes de artistas plásticos nos Estados Unidos. ${ }^{3}$

Em São Francisco, Detroit ou Nova York, a pintura de Rivera estimulou novas discussões sobre a autonomia da arte moderna e sua relação com as novas formas de capital cultural. Sobre o tema, Anna Indych López, uma das principais estudiosas da arte de Rivera nos Estados Unidos na atualidade comenta:

Rivera ocupou um lugar substancial nos Estados Unidos durante os anos 30, ainda que muito ambíguo, como resultado de sua política de esquerda. Antes de chegar a Nova York, sua presença em São Francisco "abriu um novo debate sobre a complexa relação entre os murais, a esquerda e o público". Com o surgimento de uma arte de esquerda nos Estados Unidos, sua recepção nesse país foi integrada a um diálogo mais amplo sobre o papel social do artista, a oposição entre a política marxista e a estética modernista, e o destino da arte pública.*

A projeção épica de sua pintura deslindou novas zonas de intervenção artística na era fordista. Rivera inscreveu novas técnicas e princípios pictóricos em regimes de visibilidade da alta modernidade industrial. Suas vastas alegorias projetam tentativas de solução de um dos grandes conflitos ideológicos de sua época: o desajuste dos múltiplos tempos da terra, o corpo trabalhador e a intensa modernização tecnológica que havia intensificado a transformação da cultura norte-americana desde a chamada revolução "tecnocientífica” das últimas décadas do século XIX - quando se estabeleceram as bases intelectuais e financeiras para a revolução do transporte e

\footnotetext{
${ }^{2}$ Ver os capítulos da autobiografía de Rivera sobre sua estadia nos Estados Unidos e, específicamente, o capítulo dedicado a São Francisco em: RIVERA, Diego e MARCH, Gladys. Mi arte, mi vida: una autobiografia. Mexico: Herrero, 1963. Sobre os principais murais de Rivera em SF, ver o clássico trabalho de Elizabeth Fuentes Rojas, Diego Rivera en San Francisco: una historia artistica y documental (Guanajuato, Oto.: Gobierno del Estado de Guanajuato, 1991).

${ }^{3}$ Depois da destruição do mural de Rivera no Rockefeller Center (1934) vários artistas californianos cubriram várias paredes da distinta Coit Tower ao norte da cidade de São Francisco com murais de homenagem a Rivera. Esse é um excelente exemplo de sua influência entre os artistas de W[ork]P[rogress]A[administration], de grande impacto no campo cultural - nas artes plásticas, no teatro, na fotografia e, inclusive, no cinema, até o momento da repressão macarthista da década de 1950.
}

* (LÓPEZ, Anna Indych. "Mural Gambits: Mexican Muralism in the United States and the Portable FresCo". In: Art Bulletin, 01 JUN-07.) 
as inovações do assembly line nas primeiras décadas do século XX. De fato, o espaço fabril da linha de montagem e a segmentação fordista seriam os temas da principal obra de Rivera, exposta no Instituto de Arte de Detroit. O contraponto entre o tempo administrável do trabalho e a energia física é o assunto central dos murais para Ensel Ford, pintados por Rivera em 1932. Nestes, aparecem detalhes em que as exigências de composição e estilo da forma competem com as leis da gravidade e a energia de trabalho dos corpos em tênue equilíbro. A arte de Rivera explora as condições de um equilíbrio precário entre o corpo e o trabalho mecanizado, suprindo uma espécie de compensação simbólica, precisamente, mediante a "modelização" e "formalização" artística. É uma arte da abstração, cuja ligeireza de linhas dissimula o enorme peso, a gravidade histórica, que opera e esmaga o tempo natural dos corpos nesses espaços fabris que, diga-se de passagem, por momentos, nos fazem lembrar o então conhecidíssimo Metrópolis de Fritz Lang.

Os murais de Detroit representam uma monumental reflexão alegórica sobre a segmentação do trabalho na era fordista. Revelam, como poucas obras do clássico muralista, a grande contradição de Rivera diante do potencial emancipador da tecnologia. Por outro lado, expressam seu posicionamento diante do tempo taylorizado da exploração do trabalho. Os doze painéis - que se desdobram ao longo da base das três principais paredes do mural do DIA (Detroit Institute of Art) - registram as "doze estaçôes" do tempo da montagem industrial, rigorosamente administrados. A sequência termina com silhuetas difusas, de traços caricaturais, que fazem lembrar a crítica estética da modernidade industrial presente nas árvores do expressionismo. Seu tema é o desgaste físico e a massificação, ou seja, em termos benjaminianos, a problemática moderna da dissolução da experiência.

A crítica do "trabalho alienado" não é tão notável assim nos murais californianos, em que Rivera parece encontrar mais afinidade com o "progressismo", com as paisagens do grande capital agrário. O primeiro deles, "Alegoria da Califórnia”, ainda trabalha a paisagem tecnológica sob a tutela de uma figura da abundância telúrica - uma majestosa e arcaica mãe branca - situada no centro do painel. A fusão mestiça reaparece alguns anos depois no mural da "Unidade Panamericana", depois de uma segunda viagem, onde a ficção cósmica de Vasconcelos reaparece na estranha síntese da argila e do aço, totem e indústria, que ocupa o centro do mural. 
Se foram bem frequentes os pronunciamentos de Rivera sobre a relação entre a arte e o poder durante as duas principais passagens pela Califórnia, a prática de sua pintura é muito mais significativa que os gestos do self-fashioning de Rivera no campo intelectual norte-americano. A presença de uma forma que organiza a matéria e o próprio sentido de sua prática artística revela muito mais sobre os poderes da arte (i.e., sobre a arte do poder) que o entusiasmo progressista e teleológico de seus pronunciamentos durante aqueles anos. O desenho, a composição dessas grandes alegorias, assim como o esmero com a superfície cromática de suas figuras heroicas, articularam, por um lado, a proposta de uma espécie de utopia agroindustrial para a modernidade tardia; e, por outro, estratégias de mediação entre a demanda de experimentação e de cuidado formal da arte de vanguarda que começava a dominar o mercado a as exigências de uma arte mais política e militante. Sobretudo a partir de sua retrospectiva no Museu de Arte Moderna de Nova York (1931), que era nada menos do que a segunda grande retrospectiva que se montava no recém inaugurado museu, Rivera contribuiu para a criação de novos paradigmas da cultura visual do New Deal em uma época de redefinição das relações entre Norte e Sul: época de uma profunda reconfiguração do latino-americanismo.

Norte e Sul não são coordenadas exclusivamente geográficas. Sua dualidade tem implicado, desde a sua origem nos discursos latino-americanos do século XIX - podemos tomar Bilboa e Martí como exemplos -, a oposição entre "duas culturas" assimétricas, uma submetida ao desenvolvimento tecnocientífico; outra sujeita aos "altos prazeres do espírito", segundo a celebrada frase de José Enrique Rodó em Ariel, publicado em 1900. Alerta às necessidades nacionalistas da Revolução Mexicana, Vasconcelos "racializou" a narrativa histórica implícita na visão do século XIX das "duas culturas" do Norte e do Sul. Vasconcelos reescreveu o grande relato europeu da evolução do espírito (hegeliano) visualizando o destino da "raça cósmica" em termos de fusão ou síntese mestiça como o telos de uma modernidade mexicana ou autóctone. ${ }^{4}$

O contraponto Norte/Sul estrutura a visão de Rivera, principalmente no mural da "Unidade Panamericana" do City College de São Francisco. A progressão do mural se move em duas direções

\footnotetext{
${ }^{4}$ Ver Rubén Gallo. Mexican Modernity: The Avant-Garde and the Technological Revolution. Cambridge: The MIT Press, 2010 e RAMOS, Julio, 1989. Desencontros da modernidade na América latina, loc.cit.
} 
opostas: a partir da esquerda, um movimento parte das origens toltecas e astecas; e, a partir da direita, outro movimento evoluiu com imagens da revolução tecnocientífica. Ambas direções confluem no centro do mural, onde figura o casal multirracial, procriador da mestiçagem. O casal une suas mãos sob a emblemática e monumental fusão de Coatlicue e uma peça gigantesca da linha de montagem Ford. A monstruosidade da fusão - sua relação com a ficção científica - é notável em mais de um sentido, particularmente se nos perguntarmos sobre a pintura que possivelmente teria que completar a tela, ainda vazia, que a figura de Frida Kahlo pinta no mural de Rivera, situada no painel central do mural, justo à esquerda do casal, e a ponto de pintar sobre uma tela. Veja-se, por exemplo, o "Autorretrato de Frida na fronteira entre México e Estados Unidos", pintado em São Francisco em 1932, durante a estadia anterior de Rivera e Kahlo na Califórnia. A pintura, no mesmo tom da radicalização do primeiro ecologismo (anarquista) californiano daqueles anos, rechaça qualquer tropo de "fusão" entre os dois mundos: traça a zona cinza da contaminação da terra na fronteira. Algo similar ocorre em outro quadro de Kahlo pintado durante a estadia de ambos em Detroit: "No Hospital Henry Ford". A pintura de Kahlo trabalha, de fato, a zona mais destrutiva e agressiva da era fordista, a violenta fragmentação do corpo, o retorno à superficie do mundo de uma irreprimível força totêmica e subterrânea.

É certo que, já na década de 1930, o tema das "duas culturas", tão importante, também para Octavio Paz (leitor de Heidegger) não era nada novo, mas Rivera explicita uma dimensão da oposição Norte/ Sul que Martí, por exemplo, somente vislumbrava no seu notável ensaio sobre a tecnologia e a indústria cultural, "Coney Island". As "duas culturas" se distinguem tanto em termos de cultura material quanto em relação aos padróes ou paradigmas de "modelização do real" em seus respectivos modos de vida. Martí notou em sua visita à recém-formada Coney Island, em 1883, o impacto dos novos meios de comunicação, sobretudo do jornal e do rádio, na sensibilidade dos cidadãos. Martí opunha a artificialidade daquele mundo às essências do "espírito" latino-americano. Trata-se, com efeito, dessa geografia latino-americanista - muito impactada pelo discurso cultural, estetizante - que ordena grandes zonas do pensamento latino-americano até os dias atuais. ${ }^{5}$

\footnotetext{
${ }^{5}$ Ver RAMOS, Julio, Desencontros da modernidade na América Latina. Literatura e política no século 19. Trad. Rômulo Monte Alto. Belo Horizonte: Ed. UFMG, 2008 .
} 
Rivera acrescenta um complexo painel sobre a função do cinema à sua grande obra californiana: é o quinto painel, centrado na figura de Chaplin. Este está demarcado entre dois projetores de cinema. A evidente mise-en-abyme de Rivera não somente comenta, neste caso, a realidade do fascismo, como se destacou tantas vezes, mas também o impacto dos novos meios de representação na percepção e na interpretação possível da experiência histórica. Hitler aparece entre os atores de cinema. A história se confunde com a representação midiática: algo similar ocorre com a irônica figura de Dick Tracy, inserida entre as pessoas que observam o espetáculo da montagem industrial de um carro Ford nos painéis do DIA. O efeito contradiz qualquer visão ingênua do "naturalismo" ou do fundamentalismo realista de Rivera, o qual inclui, no plano inferior do painel, uma estranha figura que remete tanto ao "Saturno" de Goya quanto ao legado goyesco na obra de E. Munch e do expressionismo alemão. O expressionismo alemão não só se opôs a Hitler: sua relação com a história do cinema e da caricatura popular é sumamente complexa, como aponta Kracauer, em seu livro sobre o cinema alemão e o nazismo no período do entreguerras.*

Minha intenção, certamente, não é sugerir um óbvio antecedente pós-moderno (na função de pastiche e simulacro) nesta pintura que, para alguns, exemplifica vários dos princípios ideológicos e formais da "arte pública" sob a influência do realismo social. $\mathrm{Na}$ verdade, interessa-me enfatizar como Rivera produz uma espécie de antropologia da cultura visual californiana durante a consolidação de Hollywood, em um momento em que o mundo da reprodução de imagens começava a problematizar qualquer forma ingênua de realismo e de demanda fundamentalista de acesso "primário” à experiência. Se Nova York continuava sendo a grande capital da modernidade industrial tardia, Los Angeles (e sua extensão em Las Vegas) emergia como a grande capital da sociedade do espetáculo ou do simulacro. É certo que o simulacro ou o desdobramento autorreferencial do discurso de Rivera não diminui o horror da experiência que a sua obra tenta comunicar, obra esta que, sem nenhuma dúvida, enfatiza a dimensão política das representaçōes, sem abster-se da pergunta sobre o fundamento ou a prioridade referida nas mesmas. Não basta, então, o consabido assinalamento desconstrutivo da secundariedade do discurso. A pergunta política é pragmática em um duplo sentido. Por um lado, revela as pugnas internas do campo da representação, como a disputa entre
* (KRACAUER, Siegfried. From Caligari to Hitler: A Psychological History of the German Film. (1947) Leonardo Quaresima (Ed.). Princeton: Princeton University Press, 2004.) 
o expressionismo de vanguarda, o nazismo, o realismo social e o cinema de massas na década de 1930, tanto na Alemanha quanto em São Francisco ou Los Angeles. Por outro, através do mesmo movimento de representação, intervém no campo de disputas sobre a "verdade" da experiência histórica, questionando a autoridade de outras posições e modos de representação.

A historiografia acadêmica da Guerra Fria - por sua conhecida tendência a impor uma distância insuperável entre a militância e a criatividade, o ativismo e a arte - tira o peso da intensificação formal e da modernidade inquestionável desta obra cujas amplas paisagens, em sua dimensão agroindustrial e utópica, perturbam as fronteiras entre as culturas do norte e do sul do continente, assim como as margens de uma noção territorializada do patrimônio nacional. A obra de Rivera criou as bases para um idioma artístico transnacional, tão alerta à geometria industrial quanto à espacialidade tolteca; tão conectada ao telurismo populista da revolução mexicana quanto às técnicas do reboco florentino.

Com efeito: como se viaja do Sul ao Norte? O que se leva na bagagem? Quais são as condiçōes que tornam possível a entrada do viajante do Sul ao Norte? Diego Rivera certamente viajou à Califórnia com uma bagagem reconhecida: um complexo arquivo imaginário. Esse acervo se constitui, em primeiro lugar, através do impacto da revolução mexicana durante os anos de sua formação, do discurso da mestiçagem e das interpelaçōes de Vasconcelos através da ficção mediadora da "raça cósmica" - desde a Secretaria de Educação Mexicana em 1921 até a época dos grandes debates sobre a "decadência do Ocidente" na Europa. Em segundo lugar, pelo reconhecimento prévio da arte renascentista italiana, das inovações de Braque e de Picasso, da inflexão etnográfica do movimento surrealista, do espírito revolucionário de 1917 e da arte russa (da crítica ao stalinismo à renúncia ao Partido Comunista). E, finalmente, por sua relação com Frida Kahlo, que o acompanhou na viagem aos Estados Unidos e que deixou um legado californiano e latino-americanista de grande destaque (cf. seu "Autorretrato na fronteira do México e dos Estados Unidos”, de 1932).

Algo mais: quando Rivera pintou o pequeno mural sobre as amendoeiras na parede da casa de Rosalyn Meyer Stern, com certeza 
conhecia o quadro azul de Van Gogh intitulado "Amendoeiras em flor". Ambas as obras, a tela mais que conhecida de Van Gogh, pintada em 1890, e o afresco de Rivera, pintado quarenta anos depois, refletem esteticamente sobre o processo da criatividade, ainda que desde perspectivas muito diferentes. No quadro, um presente para seus sobrinhos, os filhos do benfeitor Teo, Van Gogh identifica a criação do valor - a beleza da amendoeira em flor - com um efeito de morfogenia natural, sem aparente intervenção humana. Rivera, ao contrário, introduz uma dimensão pragmática ou performativa. Quer dizer, introduz a produção - uma espécie de culto ao trabalho e à prática - que, se bem registra a beleza visual (também azul) da amendoeira, insere a natureza no circuito do cultivo tecnológico, do trabalho e da circulação econômica, que também são matéria da arte de Rivera.

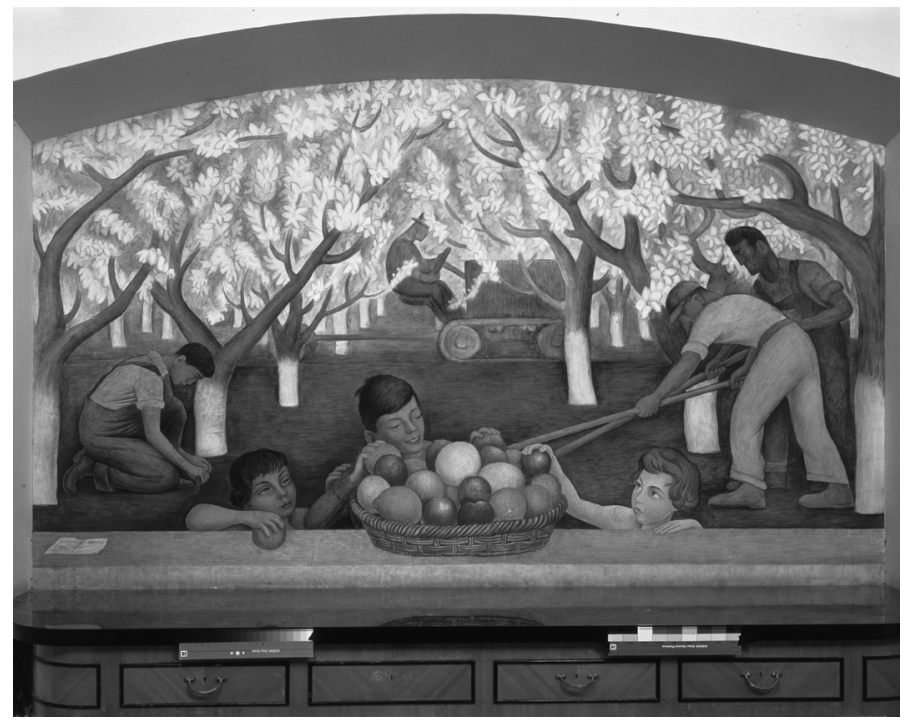

Diego Rivera. Still Life and Blossoming Almond Trees, 1931. Stern Hal, Universidade da California, Berkeley.

A transformação da perspetiva é chave: se a amendoeira em flor de Van Gogh aparece em um primeiro plano, o afresco de Rivera reorganiza radicalmente a perspectiva, multiplicando as amendoeiras em uma série. $\mathrm{O}$ cultivo industrial situa a série de amendoeiras no próprio desdobramento da profundidade da perspectiva. A perspectiva racionaliza a composição. A mancha azul de Van Gogh é citada por Rivera, mas o azul está reorganizado de acordo com 
um desenho geométrico muito marcado, delineado verticalmente e organizado de acordo com uma hierarquia estrita que designa a tékhne, ou seja, um enquadramento e disposição de sentido providos pela racionalização agrícola. Esse é precisamente o regime visual de uma tékhne industrial moderna. Seu emblema é a maquinária agrícola que centra o foco da perspectiva no plano superior do afresco; pespectiva que se desdobra para baixo em mais dois planos, cujas figuras estão também organizadas de acordo com simetrias e proporçôes espaciais muito ordenadas (a essa simetria espacial lhe corresponde, digamos, o tempo do taylorismo, parodiado por Chaplin em Modern Times, de 1936). A simetria geométrica organiza os corpos que descendem, desde o plano superior da máquina, primeiramente no triângulo que configura os três corpos do plano médio, $\mathrm{e}$ logo, abaixo (no primeiro plano) as três crianças que se preparam para intercambiar e consumir as frutas.

Desse modo, o materialismo abstrato do afresco não é necessariamente menos "idealista" que o de Van Gogh. A amendoeira de Van Gogh privilegia o instante, o efeito visual do estímulo que produz a matéria no nervo de um olho urbano; Rivera, por outro lado, submete a matéria da terra e do corpo a um esquema óticoconceitual que idealiza a produção. O cultivo é um trabalho sem desgaste nem esforço visível, desprendido dos estragos do tempo. $\mathrm{O}$ volume da matéria perde peso. Os corpos não suam; posam detidos em uma dança.

Trata-se de uma notável estetização do trabalho. Era preciso esperar o Rulfo de "Nos han dado la tierra" ["A terra que nos deram"], à sedenta narrativa texana de Tomás Rivera em ...y no se lo tragó la tierra [...E a terra não o tragou] a Vidas secas de Graciliano Ramos ou ao cinema de Glauber Rocha para presenciar o desgaste, a dança macabra do trabalho agrícola na terrinha sob a sola das botas do camponês de Van Gogh. Em contraste, os murais de Rivera elaboram uma metafísica do trabalho. A geometria industrial das proporções elocubra sobre a superação estética do desgaste físico, abstraindo ou hipostasiando o tempo de sua condição corporal que, no entanto, permanece como o suporte do valor, tanto das frutas como da arte em si (o muralista é patrono de obras públicas).

Portanto: se no plano superior aparece o trator, justo acima dos três corpos racializados do trabalho manual, é curiosamente no primeiro plano, abaixo, onde vemos o lugar da cesta de frutas colocada entre as três crianças. 
Neste momento as frutas, pela primeira vez, se tornam visíveis no quadro: prontas para o consumo. A visibilidade as dispõe para o consumo. O intercâmbio das frutas (não mais sua produção) possibilita o contato entre as multiplicidades dos corpos e as marcas da diferença (cor, altura, volume, idade). A fruta circula entre a menina branca, o menino e a menina de pele escura. A fruta é um elo, um shifter, entre os planos da multiplicidade. Não é meramente um "objeto"; é o que Michel Serres chama de um "quase objeto", um objeto que possibilita uma rede de relações subjetivas em seu entorno. É, como signo intercambiável, a condição da própria comunicabilidade. Como signo intercambiável - e ponto de articulação entre as diferenças - é uma cifra de valor e de beleza. A beleza para Rivera está ligada a essa articulação. Portanto, se para Rivera a pintura é um trabalho de explicitação do trabalho, ou seja, um desvelamento do que a estética "burguesa" não mostrava (o cultivo da cultura da amendoeira em flor: o trabalho como condição da estética) na bodega ou na still life, seu quadro, tão idealizador do trabalho - no dissímulo do desgaste do corpo trabalhador -, volta a situar a visibilidade bela no plano do intercâmbio e consumo de objetos.

\section{III}

Certamente, o circuito do intercâmbio não termina nessa superfície disciplinada da harmonia no afresco de Rivera. O circuito da ressignificação das frutas também não termina com essa instância do multiculturalismo light explicitada por uma interpretação recente que Robert Brigneau, atual reitor (chancellor) da Universidade da Califórnia, em Berkeley, faz da leitura de Rivera: ele interpreta emblematicamente a presença do mural no campus universitário como símbolo de uma universidade "engajada" - engaged - com uma missão pública.

Que relação se estabelece entre a parte e o tempo fragmentado da fruta (propriedade, trabalho ao sol, consumo) e o "todo" universitário da "universidade comprometida"? Como a universidade produz o seu símbolo? O reitor Brigneau instrumentaliza o afresco de Rivera, que permanece quase desconhecido em um recanto do campus. Brigneau, de fato, dilui o memorável passado do ativismo social da cidade e a militância estudantil de Berkeley nessa leitura multiculturalista light que converte o trabalho de um artista do Sul 
em uma espécie de relíquia ou sinédoque de uma "comunidade" não existente. Tudo isso se dá em uma época de despolitização universitária, que dá agigantados passos no sentido da privatização de uma grande universidade de tradição pública; época de ineficientes estratégias de administração empresarial da educação e de anulação $\mathrm{da}$ autonomia de trabalhos intelectuais e cidadãos do claustro.

A interpretação culturalista do reitor, publicada no número de inverno de 2008 da revista The Promise of Berkeley [A promessa de Berkeley] (revista publicitária da UCB) sobre a missão social da educação em Berkeley, obstrui os elementos-chave da multiplicidade presentes no afresco de Rivera. Primeiro, o reitor indica que as crianças do quadro são os netos e sobrinhos de Rosalie Meyer Stern. A culturalização nega a evidente diferença racial (matéria do racismo): um dos aspectos do conflito agroindustrial que tenta superar a sublimação do trabalho na pintura de Rivera. A raça é a matéria sublimada pela culturalização do conflito. Segundo, a interpretação do reitor se escreve durante os mesmos meses em que o Congresso norte-americano debate em Washington sobre a criminalização dos imigrantes sem documentos; debate-se e reduz-se a condição jurídica, médica e educativa dos dez milhōes de imigrantes sem documentos que sustentam, entre outras coisas, a economia agrícola do país, sobretudo na Califórnia, o maior abastecedor de frutas e alimentos dos Estados Unidos.

Permitam-me enfatizar o ponto: a culturalização é a instância do consumo culturalizado do desejo (de contato e intercâmbio). Não é simplesmente uma instância óbvia da instrumentalização multicultural da arte ou da cultura da América Latina em uma universidade do "Norte". Já conhecemos muito bem essa história. ${ }^{6}$ Trata-se do efeito concomitante da estetização, da harmonização do corpo e do consumo cultural e material acarretado pelos mesmos intelectuais do "Sul" - neste caso, nada menos que um clássico indiscutível da "esquerda latino-americana" - nessa espécie de utopia industrial e agrícola, muito afinada com a própria esté-

\footnotetext{
${ }^{6}$ Ver MOREIRAS, Alberto. A exaustão da diferença. A politica dos estudos culturais latino-americanos. Trad. Eliana Lourenço de Lima Reis e Gláucia Renate Gonçalves. Belo Horizonte: Ed. UFMG, 2001; CAMPA, Román de la. Latin Americanism. Minneapolis: Minnesota University Press, 2000; e RAMOS, Julio. Desencontros da modernidade na América Latina. Literatura e politica no século 19, loc.cit.
} 
tica modernizadora de seus painéis mais clássicos, encomendados pelo estado mexicano.

A culturalização do desejo opera como mediadora entre o Norte e o Sul nas disciplinas humanísticas mais tradicionais, nos estudos culturais ou literários e, particularmente, nas complexas redes de comunicação transnacional possibilitadas pela tradução ou pelo ensino da língua espanhola nos Estados Unidos.

\section{IV}

Os estudiosos da antiga tópica ut pictura poiesis insistem no tema dos grandes desejos insatisfeitos e mutuamente exclusivos da pintura e do discurso verbal: é tão impossível falar com imagens como pintar com palavras. No entanto, a história da tópica horaciana da pintura que fala, ligada à tradição da ekphrasis, está povoada de exemplos sobre a função metafórica de objetos que, na pintura, indicam as funções do intercâmbio verbal (assim como os truques gráficos para a representação pictórica-concreta - na poesia). As frutas são uma dessas metáforas, não só por serem cifras do intercâmbio e economia do desejo (A Fruta), senão também por sua relação metonímica com a oralidade. A fruta roça, como a palavra, o paladar.

Assim, qual poderia ser a palavra que se intercambia no lugar da reciprocidade onde a menina recebe a fruta do menino na pintura de Rivera? Em que língua se comunicam os três sujeitos da multiplicidade e cumplicidade californiana? Convém insistir na lógica de intercâmbio e reciprocidade da cena da entrega da fruta. Os olhos carmelitas da menina menor formam um quiasmo perfeito com os olhos azuis da menina de pele escura e olhos chineses. Que palavras intercambiam? Se os olhares e as cores dos olhos se cruzam, por que não haveriam de trançar as palavras? Será porque as palavras, como as raças, não se misturam? Ao terror conhecido como Próspero (o insulto de Caliban), há que acrescentar agora uma dimensão ainda pouco explorada: o espanto de que Miranda, a menina branca, aprenda primeiro a língua do menino Caliban, antes mesmo que sua "própria" língua, ou que crescesse bilíngue, embaixo da saia de uma babá sem documentos de residência, aprendendo a palavra "amor" em uma língua submetida e subalterna.

Alguns anos depois da estadia de Diego Rivera na Califórnia, Octavio Paz visitava a cidade de Berkeley. Paz viajava a Berke- 
* (PAZ, Octavio. El laberinto de la soledad. México: Fondo de Cultura Económica, $1959,2^{a}$ edição, $14^{a}$ reimpressão: 17.) ley de Los Angeles, onde havia presenciado a "orfandade" pachuca. Escreve Paz em O labirinto da solidão:

Lembro que uma amiga a quem fazia notar a beleza de Berkeley me dizia: "Sim, isto é muito belo, mas não consigo compreendê-lo de todo. Aqui até os pássaros falam inglês. Como você quer que eu goste das flores se não conheço seu nome verdadeiro, seu nome em inglês, um nome que se fundiu até mesmo nas cores e nas pétalas, um nome que já é a coisa em si? Se eu digo buganvília, você pensa nas que viu em seu povoado [...]. E a buganvilia forma parte de seu ser, é uma parte de sua cultura, é isso que você lembra depois de tê-la esquecido. Isto é muito lindo, mas não é meu, porque o que a ameixeira e os eucaliptos dizem não o dizem para mim, nem a mim eles me dizem.*

O tema da perda radical, a orfandade, que Paz adjudica ao pachuco, se fundamenta em um essencialismo linguístico. Os pachucos são os que supostamente perderam sua língua, sua herança. A história recente da globalização confirma algo muito diferente do que percebeu Paz: Los Angeles e Nova York se encontram entre as cidades de maior número de hispanófonos do planeta. Fala-se nos múltiplos registros de uma língua globalizada, duplamente estrangeirizada ou diminuída: primeiro é estrangeirizada ou diminuída pelo estado, que nunca reconheceu seu potencial cidadão (apesar de que o mercado reconheça, é claro, seu potencial econômico); e, segundo, é subalternizada pelos marcos territoriais e eurocêntricos (e latino-americanistas) do hispanismo oficial que têm profissionalizado e instrumentalizado a realidade planetária do espanhol como uma língua global.

Herdeiro do culturalismo das nostalgias imperiais promovidas depois da guerra de 1898,7 o hispanismo oficial exerce, ainda hoje, uma influência notável sobre o imaginário geopolítico dos estudos literários latino-americanos, tão marcados pelo legado filológico e pensamento linguístico de figuras como Pedro Henríquez Ureña; dos alunos de Raimundo ou María Rosa Lida; ou, até mesmo, do próprio Alfonso Reyes - figuras canônicas do nosso campo, aludidas recentemente pelo linguista dominicano Juan R. Valdéz em sua excepcional tese sobre o pensamento linguístico de Pedro Henríquez Ureña e as ideologias em torno dessa construção

\footnotetext{
${ }^{7}$ Ver QUIÑONES, Arcadio Díaz. "1898: Hispanismo y guerra”. In: Walther L. Bernecker (ed.) 1898: su significado para Centroamérica y el Caribe. Berlin: Vervuert Verlag: 17-35.
} 
imperial, tão abstrata como realmente efetiva, que chamamos de língua espanhola.*

"Nós" mesmos, professores da língua, temos descuidado da condição pragmática e do potencial político da teoria no ensino da língua, fomentando, algumas vezes, uma profunda divisão do trabalho e uma oportuna autonomia do estudo literário ou "teórico", separados da abundância vital e política do ensino da língua. No entanto, de que "nós" falamos aqui? "Aqui", de onde escrevo - em um estado multilíngue como o da Califórnia -, ao propor o ensino do espanhol como língua diásporica que atravessa frequentemente (sem documentos) as óbvias distinçōes entre "Norte" e "Sul" (do clássico discurso latino-americanista), supomos, por sua vez, que como língua diaspórica, impactada - como argumenta José del Valle - pela globablização, é uma língua em permanente contato com a realidade de outras línguas: não só com o inglês, claro, senão também com as línguas indígenas contemporâneas de milhares de trabalhadores nos campos e cidades californianas, onde o mixteco, o zapoteco e sobretudo o maya-yucateco não são simplesmente matéria arqueológica do passado, mas línguas vivas cujas vozes transitam no espanhol em sua dispersão diaspórica. Não precisamos dos debates eurocêntricos sobre a subordinação de "particulares", sob a prioridade de uma coerência universal (Laclau, Badiou), para saber que estamos diante de um problema inevitável no sistema escolar californiano, em que o grupo etnolinguístico majoritário é de origem "hispânica". A indústria da língua espanhola sonha aqui e no Brasil com o monopólio desse mercado escolar que requer não somente a produção de livros de texto, como também a manutenção de um paradigma ideológico e de uma política do "bem" linguístico. O questionamento do hispanismo tem sido até hoje, salvo poucas exceções, um debate intelectual, universitário. A discussão sobre o hispanismo entra agora em uma fase de crítica institucional inadiável. A língua acarreta a história de suas subordinações.

\section{V}

A fruta passa pelo paladar e pelo amor da língua. $\mathrm{O}$ amor da língua é a loucura da filologia, loucura segundo a consabida fórmula lacaniana, porque oferece o que não pode ser dado, o que nunca se teve nem se podia ter: um modelo estável e fundamentado de lín-

* (VALDÉZ, Juan R. Language, race, and identity in Pedro Henríquez Ureña's Dominican oeuvre: A study on language ideologies. Tese de doutorado. City University of New York, 2008.) 
gua. ${ }^{8}$ É o mal-estar do desejo fáustico do filólogo que Coppola dramatiza em seu filme Youth Without Youth [Velha Juventude, 2007], construído com base em um binômio moderno: ou a língua ou a vida. Hoje nos cabe exigir algo distinto: o ensino da língua viva como condição do desejo e da vitalidade política.

Agora então como um jovem professor de línguas se recupera desse antigo mal-amor filológico? Conhecendo profundamente seu mal, responde uma poeta:

Estoy aqui, sentada, con todas mis palabras como con una cesta de fruta verde, intactas.

Los fragmentos

de mil dioses antiguos derribados

se buscan por mi sangre, se aprisionan, queriendo recomponer su estatua.

De las bocas destruidas quiere subir hasta mi boca un canto un olor de resinas quemadas, algún gesto de misteriosa roca trabajada.

Pero soy el olvido, la traición, el caracol que no guardó del mar ni el eco de la más pequeña ola. $Y$ no miro los templos sumergidos; sólo miro los árboles que encima de las ruinas mueven su vasta sombra, muerden con dientes ácidos el viento cuando pasa.

$Y$ los signos se cierran bajo mis ojos como la flor bajo los dedos torpisimos de un ciego. Pero yo sé: detrás de mi cuerpo otro cuerpo se agazapa, $y$ alrededor de mi muchas respiraciones cruzan furtivamente como los animales nocturnos en la selva. Yo sé, en algún lugar, lo mismo que en el desierto el cactus, un constelado corazón de espinas, está aguardando un hombre como el cactus la lluvia. Pero yo no conozco más que ciertas palabras en el idioma o lápida bajo el que sepultaron vivo a mi antepasado. ${ }^{9}$

\footnotetext{
${ }^{8}$ Ver o formidável ensaio de Jean Claude Milner, El amor por la lengua (1978) (México: Nueva Imagen, 1980). Há também a nova edição da Visor, de 1999.

9 "Estou aqui sentada, com todas as minhas palavras/ como com uma cesta de fruta verde, intactas./ Os fragmentos/ de mil deuses antigos derrubados/ buscamse por meu sangue, aprisionam-se, querendo/ recompor sua estátua./ Das bocas
} 
Esse poema de Rosario Castellanos explicita o peso associativo que possuía a fruta no esquema visual e mudo das artes plásticas: tropo do paladar, vizinho da língua, prova-se e tem gosto na boca (embora seja certo que às vezes a pintura nos agarra, como os professores de língua, pela orelha). Mas, se no mural de Rivera a fruta se torna visível (como signo) somente no momento do intercâmbio - em um harmônico jogo de reciprocidade infantil, intercâmbio da primeira palavra em outra língua ou do primeiro beijo -, o poema de Castellanos, em contraste, introduz uma nova dimensão: a violência e o esquecimento como condição do intercâmbio, quer dizer, o intercâmbio mesmo do discurso sobre o amor ou a perda da língua.

Castellanos - o sobrenome paterno a arrasta - se situa no lugar de "traição, esquecimento": o lugar da tradutora. ${ }^{10} \mathrm{O}$ amor da língua estabelece o estrepitoso drama da traição. Não é esse, precisamente, o ponto de desfecho de Balín Canán (1957), o primeiro romance de Castellanos, quando a menina narradora pensa que seu desejo foi a causa da morte de seu irmão menor, Mário, o herdeiro do legado e do arquivo paterno? O que se faz depois da morte ou desaparecimento do outro? Escrever para expiar a culpa? A traição e a culpa se encontram entre os tópicos mais silenciados do latinoamericanismo, particularmente em sua zona de mediação letrada, como em El zorro de arriba y el zorro de abajo de Arguedas, no qual a culpa leva à impotência e ao esgotamento final da vida. A culpa é a pulsão mortal do latino-americanismo.

destruídas/ quer subir até minha boca um canto/ um cheiro de resinas queimadas, algum gesto/ de misteriosa rocha trabalhada./ Mas sou o esquecimento, a traição,/ o caracol que não guardou do mar/ nem o eco da menor onda./ E não olho os templos submersos; / só olho as árvores em cima das ruínas / movem sua vasta sombra, mordem com dentes ácidos/ o vento quando passa./ E os signos se fecham sob meus olhos como/ a flor sob os dedos desajeitados de um cego./ Mas eu sei: atrás/ de meu corpo outro corpo se agacha,/ e ao redor de mim muitas respiraçôes/ cruzam furtivamente / como os animais noturnos na selva./ Eu sei, em algum lugar, / o mesmo/ que no deserto o cacto,/ um constelado coração de espinhas,/ está aguardando um homem como o cacto a chuva./ Mas eu não conheço mais que certas palavras/ no idioma ou lápide/ sob o que sepultaram vivo ao meu antepassado."

${ }^{10}$ Ver ALARCÓN, Norma. Ninfomania: El discurso feminista en la obra poetica de Rosario Castellanos (Madrid: Pliegos, 1992). Sobre o tropo da traição-tradução, ver ALARCÓN, Norma. "Traduttora, Traditora: A Paradigmatic Figure of Chicana Feminism”. In: Inderpal Grewal and Caren Kaplan (Eds). In: Scattered Hegemonies: Postmodernity, Transnational, Feminist Practices. Minneapolis: University of Minnesota Press, 1994:110-136.
* (CASTELLANOS, Rosario. "Silencio cerca de una piedra antigua", Poesía no eres tú. Obra poética 1948-1971, México, Editorial Fondo de Cultura Económica, 2004: 65-66.) 
Digamos, para evitar o drama, que no caso de Castellanos o primeiro esquecimento recorda muito bem as letras do nome de um clássico do latino-americanismo na poesia: Pablo Neruda. Escreve Castellanos:

Los fragmentos

de mil dioses antiguos derribados

se buscan por mi sangre, se aprisionan, queriendo

recomponer su estatua.

De las bocas destruidas

quiere subir hasta mi boca un canto $[. . .]^{* 11}$

Não posso me deter aqui na análise pontual de quatro aspectos da elaboração metafórica (latino-americanista) em ambos os poemas: primeiro, o vocabulário fúnebre; segundo, a referência à voz e ao canto fantasmático; terceiro, os estratos geológicos e arqueológicos; e quarto, o lugar mediador do sujeito poético situado entre a fragmentação e a recomposição do passado, o esquecimento e a memória monumental.

Trata- se evidentemente de dois poemas muito diferentes. "Aqui estoy, sentada" ["Aqui estou, sentada"] posiciona o sujeito no poema de Castellanos em contraste enfático com a viagem épica de Neruda. A precisão do deíctico, "aqui", situa o corpo no lugar da enunciação, em contraste tanto com o alto voo de Neruda como com a vontade de saber e os esquemas óticos da viagem espistemológica do Primero sueño [Primeiro sonho] de Sor Juana. O poder interpretativo da poesia se anula na cegueira, à que segue, no entanto, outro tipo de conhecimento. "Pero yo sé" ["Mas que sei eu"]. O que se pode saber na escuridão contemporânea?

Neruda havia publicado seu Canto general precisamente no México, em 1950, livro exemplar e de maior influência na poesia social ou engajada latino-americana até bem entrado nos anos 1960 . Se em "Alturas de Macchu Picchu" (1948) o sujeito empreende uma viagem épica em busca das origens, da arkhé, entre as ruínas imperiais, a voz de Castellanos se situa em um lugar muito preciso da enunciação, o "aqui" do corpo da mulher "sentada". Assim se dá o primeiro passo no sentido de uma pragmática da língua: aponta as condições de sua localização física. Esse lugar, entretanto, é o lugar de um silêncio muito íntimo portador de apenas uma antecipação:

\footnotetext{
11 "Os fragmentos/ de mil deuses derrubados/ se buscam pelo meu sangue, se aprisionam, querendo/ recompor sua estátua/ Das bocas destruídas/ quer subir até minha boca um canto [...]."
} 
a palavra ainda não é uma inscrição, uma forma ou uma categoria. Recordemos o final do poema de Neruda: "hablad por mis palabras y mi sangre" ["fale por minhas palavras e meu sangue"]. Em contraste, no poema de Castellanos o verso "quiere subir hasta mi boca un canto" ["quer subir até minha boca um canto"] torna-se pugna, balbucio e ao mesmo tempo desarma decididamente, com esse mesmo balbucio, o apelo da totalização do clássico.

Diremos, então, que se trata de um texto indigenista? Depende do que queremos dizer com "indigenismo". Se entendemos por indigenismo - como Rama, Conejo Polar, Rowe, Lienhard e outros o drama e as instituições da "tradução" e da mediação da mestiçagem ou da transculturação letrada, esse poema de Castellanos abre um caminho novo e registra o limite do indigenismo institucional no México, como crítica das operações retóricas que fundamentam a mediação. Los ríos profundos de Arguedas, poema que pode ser lido junto com o romance Balún Canán, registra o desenlace de um dos grandes "relatos" legitimadores do latino-americanismo: a ficção de representatividade da voz subalterna, não só na literatura indigenista ou no americanismo de Martí ou Neruda, senão também nas retóricas políticas do populismo "testemunhal".

Castellanos leva essa ficcção dominante ao limite e a seu ponto cego: o limite hispânico do latino-americanismo. "Fale por minhas palavras e meu sangue" é o imperativo de Neruda em uma língua que não responde ao destinatário da interpelação. Castellanos situa a voz no reconhecimento (em seu caso e no caso de Neruda, um reconhecimento fúnebre) de que a língua tem sido lavrada como uma pedra pelo esquecimento das vozes, marca dos sujeitos que a transitam.

Esse não é um dos amores da língua? A força que impulsiona a entonação do poema de Castellanos, na "escuridão", postula sem titubear a opção de um outro saber fundado não na representação, mas nas éticas de participação e justiça. Os poetas às vezes são capazes de antecipar as línguas do porvir. O jovem professor da língua nova os escuta.

Tradução de Renata Pontes

(Universidade de Buenos Aires) 
Julio Ramos é professor emérito do Departamento de Espanhol e Português da Universidade da Califórnia em Berkeley. Autor, dentre outros, de Desencontros da modernidade na América Latina. Literatura e política no século 19 (México, 1989; tradução brasileira: ed. UFMG, 2008); Paradojas de la letra (Caracas, 1996). Editor de Amor y anarquía. Los escritos de Luisa Capetillo (Río Piedras, 1992). 